\title{
Why are hospital doctors not referring to Consultation-Liaison Psychiatry? - a systemic review
}

\author{
Kai Yang Chen ${ }^{1,2^{*}} \mathbb{D}$, Rebecca Evans ${ }^{1}$ and Sarah Larkins ${ }^{1}$
}

\begin{abstract}
Background: Consultation-Liaison Psychiatry (CLP) is a subspecialty of psychiatry that provides care to inpatients under non-psychiatric care. Despite evidence of benefits of CLP for inpatients with psychiatric comorbidities, referral rates from hospital doctors remain low. This review aims to understand barriers to CLP inpatient referral as described in the literature.

Methods: We searched on Medline, PsychINFO, CINAHL and SCOPUS, using MESH and the following keywords: 1) Consultation-Liaison Psychiatry, Consultation Liaison Psychiatry, Consultation Psychiatry, Liaison Psychiatry, Hospital Psychiatry, Psychosomatic Medicine, the 2) Referral, Consultation, Consultancy and 3) Inpatient, Hospitalized patient, Hospitalized patient. We considered papers published between 1 Jan 1965 and 30 Sep 2015 and all articles written in English that contribute to understanding of barriers to CLP referral were included.

Results: Thirty-five eligible articles were found and they were grouped thematically into three categories: (1) Systemic factors; (2) Referrer factors; (3) Patient factors. Systemic factors that improves referrals include a dedicated CLP service, active CLP consultant and collaborative screening of patients. Referrer factors that increases referrals include doctors of internal medicine specialty and comfortable with CLP. Patients more likely to be referred tend to be young, has psychiatric history, live in an urban setting or has functional psychosis.

Conclusion: This is the first systematic review that examines factors that influence CLP inpatient referrals. Although there is research in this area, it is of limited quality. Education could be provided to hospital doctors to better recognise mental illness. Collaborative screening of vulnerable groups could prevent inpatients from missing out on psychiatric care. CLP clinicians should use the knowledge gained in this review to provide quality engagement with referrers.
\end{abstract}

Keywords: Consultation-Liaison Psychiatry, Hospital psychiatry, Barriers to referral, Consultation inpatient

\section{Background}

In 2012, The Australian Institute of Health and Welfare reported that people with comorbidity of any mental health and physical illness were significantly more likely to be hospitalised than people with only a mental health condition, or only a physical illness [1]. The prevalence of mental illness among hospital inpatients ranged from 26.1 to $38.7 \%$ [2-5]. Among the mental illnesses found among inpatients, prevalence of depression varied from

\footnotetext{
*Correspondence: kaiyang.chen@my.jcu.edu.au

1James Cook University, 1 James Cook Drive, Townsville QLD 4811, Australia

${ }^{2}$ Townsville Hospital and Health Service, 100 Angus Smith Drive, Townsville

QLD 4814, Australia
}

(c) The Author(s). 2016 Open Access This article is distributed under the terms of the Creative Commons Attribution 4.0 International License (http://creativecommons.org/licenses/by/4.0/), which permits unrestricted use, distribution, and reproduction in any medium, provided you give appropriate credit to the original author(s) and the source, provide a link to the Creative Commons license, and indicate if changes were made. The Creative Commons Public Domain Dedication waiver (http://creativecommons.org/publicdomain/zero/1.0/) applies to the data made available in this article, unless otherwise stated.

\section{mated around $5.8 \%$ [2].}

Hospital inpatients with any psychiatric comorbidity are more likely to utilise health care resources than those with only medical conditions. Levenson and colleagues found that patients with psychopathology or pain had longer hospital stays, more procedures performed and incurred more hospital charges [11]. Saravay and associates demonstrated in a prospective study that severity of the psychiatric comorbidity was associated with the length of stay in hospital [12]. Patients with cognitive impairment also have increased length of stay [13-15]. 
Consultation-Liaison Psychiatry (CLP) may help to improve outcomes for inpatients with psychiatric comorbidities. CLP is defined as a subspecialty of psychiatry that provides psychiatric education and care to non-psychiatric departments of a general hospital [16-18]. CLP may also provide psychiatric clinical care to patients in primary care settings [19]. The aim of CLP is to address the mental health needs of patients who are being treated in a nonpsychiatric setting.

Involvement of CLP had been shown to improve outcomes in several subsets of inpatients. In fact, elderly patients with a fractured femur, with liaison psychiatrist input, were twice as likely to be discharged home and had a shorter length of stay, compared to patients with no psychiatric involvement [20]. Desan and his colleagues found that psychiatric consultation reduces length of stay for medical inpatients [21]. Furthermore, Cassem and Hackett showed that coronary care patients who were referred for psychiatric consultation were three times less likely to die compared to the rest of the coronary care unit [22].

Despite mounting evidence supporting the involvement of CLP for inpatients with psychiatric comorbidities, referral rates from treating doctors remain low at 0.72 to $5.8 \%$ [23-29].

This study aims to present a systematic review on barriers to referral to CLP in the hospital or inpatient setting.

\section{Methods}

This review systematically identified the relevant literature using predefined search and inclusion strategies per MOOSE guidelines.
A systematic search was conducted through electronic databases including MEDLINE, PsychINFO, CINAHL and SCOPUS for articles published between 1 January 1965 and 30 September 2015.

Search terms generated were used in all different variants, singular or plural forms and included MESH and free text terms. These included: (1) Consultation-Liaison Psychiatry, Consultation Liaison Psychiatry, Consultation Psychiatry, Liaison Psychiatry, Hospital Psychiatry, Psychosomatic Medicine, (2) Referral, Consultation, Consultancy and (3) Inpatient, Hospitalised patient, Hospitalized patient. Articles that included all the above search terms ( 1 and 2 and 3 ) in abstract or title were screened.

Bibliographic screening of included articles was also performed to identify further articles.

Inclusion criteria for articles included: (1) published in English language, and (2) contributes to understanding barriers to CLP referral.

Exclusion criteria for articles included: (1) Non-English publication, (2) Non-human trials, or (3) Non-adult population, or (4) Did not contribute to furthering understanding of barriers to CLP referral.

\section{Results}

The process in which articles were found and excluded is summarised in Fig. 1.

A summary table of the thirty-five articles included for analysis can be found in Appendix. A thematic review of the barriers and enablers of CLP referrals from these 35 articles was conducted. We grouped these factors into three categories: (1) Systemic factors; (2) Referrer factors; (3) Patient factors. For each category's item, we

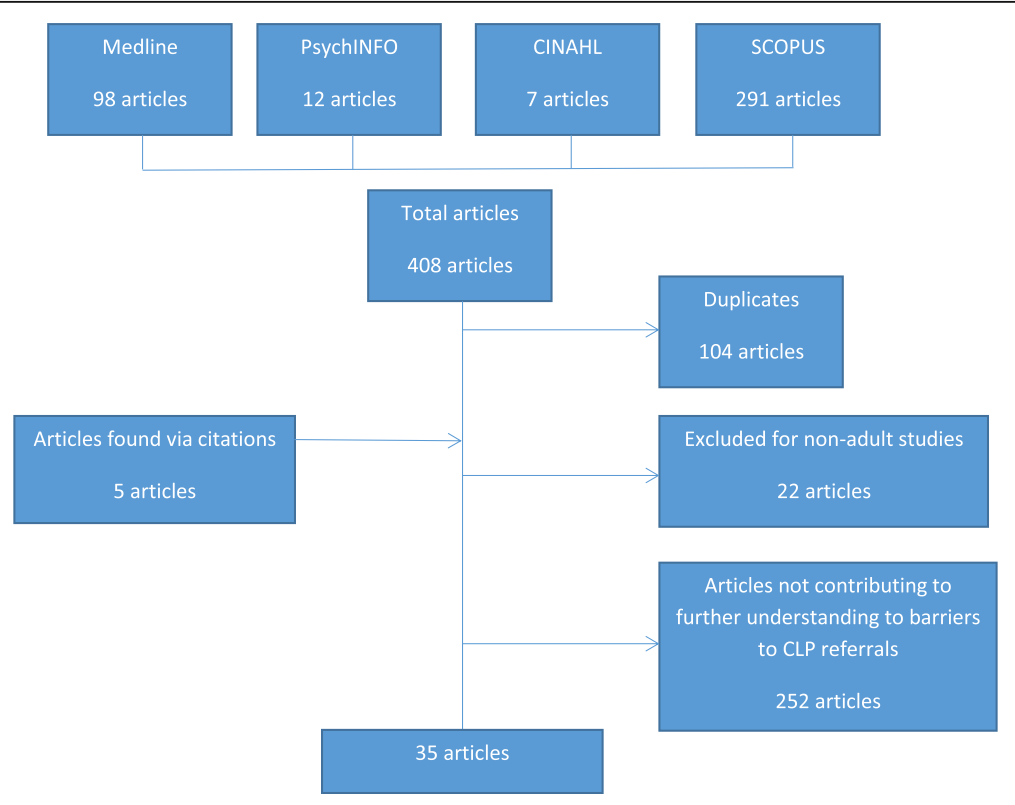

Fig. 1 Selection of articles by search strategy 
gave an indication of whether it has an influence to increase or decrease CLP referral.

\section{Systemic factors}

Systemic factors are defined as the environment factors (external to the hospital doctors or the patients). The systemic factors that influence CLP referrals are summarized in Table 1.

In a naturalistic longitudinal study based in Glasgow, Brown and his colleagues took advantage of the introduction of a new resident CLP team and studied the referral patterns over a period of 7 years [30]. The psychiatric needs of the hospital were previously met by psychiatrists from an associated psychiatric hospital and not a dedicated CLP team. It was found that referral rates increased over the study period, with a disproportionate increase in referrals of inpatients who were not involved in acts of deliberate self-harm. They suggested that the increase in referrals were due to the presence of a dedicated CLP unit. These results were replicated in one other similar study that looked at referral rates after introduction of a CLP unit [31]. Accessibility to a CLP service was also mentioned in several surveys [32, 33] as a factor that may increase CLP referrals.

The presence of a dedicated CLP team may not be adequate. Collaborative screening of inpatients with their treating team can further increase referral rates. In a Swiss study, twice weekly multidisciplinary meetings were held on a medical ward, involving psychiatrist, medical consultant and nurses. It was found that referral rates increased from 4 to $32 \%$ when collaborative screening of patients was done [34]. In addition, active engagement of medical teams by CLP consultant is suggested to increase referrals in a one year single-site German observational study [35], although active engagement was not clearly defined.

Lacking a strategy towards management of psychiatric patients may contribute to low referral rates. It was found that past suicide attempts were not correlated with psychiatric referral in South Korean hospitals [36]. Authors of this study attributed this to a

Table 1 Systemic factors possibly influencing referrals to CLP

\begin{tabular}{ll}
\hline Systemic factors & \\
\hline Increase CLP referral & $\begin{array}{l}\text { 1. Presence of dedicated CLP Service [30-33, 35] } \\
\text { 2. Active engagement of CLP consultant [35] }\end{array}$ \\
$\begin{array}{ll}\text { 3. Collaborative screening of inpatients [34] } \\
\text { Decrease CLP referral }\end{array}$ & $\begin{array}{ll}\text { 1. Lack of detailed suicide prevention strategy } \\
{[36,37]}\end{array}$ \\
$\begin{array}{ll}\text { Unclear influence } & \text { 2. Poor CLP communication [32] }\end{array}$ \\
$\begin{array}{ll}\text { 2. Work pressure [38] }\end{array}$
\end{tabular}

lack of strategies for detailed suicide prevention in Korean emergency departments and possible prejudice towards psychiatric consultation. This was supported by the fact that studies in countries other than South Korea had found suicide attempts to be predictive of referrals [37].

Limited work hours were suggested to be impacting on referrals to CLP. Caplan and his team suggested that there may be increased tendency by referrers to outsource the building of doctor- patient relationships to CLP [38]. The impact of work pressure may decrease referral rates by limiting the referrer's time or resources to manage a CLP referral. It cannot be concluded at this time if work pressure affects referral as there were no studies looking at correlation of workload of referrer and referrals to CLP.

When close collaborative work with a psychiatrist is not possible, liaison work by mental health nurses may increase referral rates. There were no studies that considered the association of referral rates with the presence of a mental health nurse. One article that described the experience of mental health nurse liaison in a head-and-neck cancer unit, reported some subjective benefits [39]. The referral patterns were not clear in this study, but the authors suggested that referral rates were more dependent on the cancer unit staff on-shift, rather than presence of mental health nurse. Further elaboration of how referral is more associated with some ward staff was not done in this report.

\section{Referrer factors}

Referrer factors are factors that are associated with the characteristics of the practitioners who may potentially utilise CLP services by referring their hospital patients. These factors are summarised below (Table 2).

Table 2 Referrer factors possibly influencing referrals to CLP

\begin{tabular}{|c|c|}
\hline Referrer factors & \\
\hline Increase CLP referral & $\begin{array}{l}\text { 1. Internal medicine speciality }[33,40,52-55] \\
\text { 2. Positive attitude towards CLP }[35,41] \\
\text { 3. Discomfort in competency assessment } \\
\text { and management [57] }\end{array}$ \\
\hline Decrease CLP referral & $\begin{array}{l}\text { 1. Young age [33] } \\
\text { 2. Stigma }[32,33] \\
\text { 3. Belief that other mental health } \\
\text { professionals may do equally well [32] } \\
\text { 4. Patient preference [33] } \\
\text { 5. Poor rapport with psychiatrist [33] } \\
\text { 6. Belief that referrer can manage without } \\
\text { psychiatric help [40] } \\
\text { 7. Poor recognition of mental illness } \\
\text { [33,42-51,54] }\end{array}$ \\
\hline Unclear influence & $\begin{array}{l}\text { 1. Different expectation of CLP service } \\
\text { delivery [56] }\end{array}$ \\
\hline
\end{tabular}


Few studies attempted to investigate barriers to CLP referral from the referrer's perspective. In 1990, Thompson and associates found through a survey of 200 hospital doctors (response rate of $35 \%$ ), that physicians agreed upon three main reasons for not referring for psychiatric consultations [32]. These three reasons were stigma, poor communication from psychiatrists and a belief that other mental health professionals may do equally well for the patient's health at reduced cost. It was difficult to assess the quality of this study given the process for survey development and validation (if conducted) was not outlined. No statistical analysis of data was reported.

In 1971, Mezey and Kellett conducted a survey with 106 hospital consultants using a modified survey previously used with general practitioners in 1966 [33]. Patients' preference not to be referred was identified as the most common barrier to psychiatric referral. Stigma was the second most common reason, followed closely by poor access to services, and inadequate rapport with psychiatrists. Mezey and Kellett also analysed the demographics of the surveyed participants and suggested that older consultants were less likely to recognise psychiatric comorbidities in their patients, while younger consultants were more likely to have inadequate rapport with the psychiatrist. Surgeons and gynaecologists were less likely to refer than their physician counter-parts. Mezey and Kellett were unable to explain this difference between specialties in their survey.

In 1982, through a survey of 400 hospital doctors (including physicians and surgeons) in North Carolina Memorial Hospital, Cohen-Cole and Friedman realised that hospital doctors do not refer most of their patients identified with significant psychological issues [40]. In the same survey, $78 \%$ of hospital doctors felt comfortable handling these psychological issues without psychiatry consultation. In addition, Cohen-Cole and Friedman found that attending physicians in internal medicine (62\%) and family medicine (43\%) tend to estimate more psychological components affecting their patients compared to surgeons (30\%), obstetriciansgynaecologist (19\%) and paediatricians (29\%).

The positive attitude of the hospital doctors towards a CLP service may increase referrals. In a 2015 survey by Hamdieh and team based in Iran, hospital doctors who had positive attitude towards their CLP service were more comfortable in making psychiatric referrals [41]. This result was supported by a one year single-site study of a German CLP service. Following one year of active engagement by the same CLP consultant, it was suggested that referrers were more comfortable with a psychiatric approach with their patients, resulting in more referrals [35].
While there might be differences in recognition of mental illness between specialties, a methodologically sound meta-analysis of 36 prevalence studies suggests that overall recognition of depression by nonpsychiatric hospital doctors is lacking [42]. Overall sensitivity was found to be $36.4 \%$ and specificity was $83.7 \%$. In 1995, in a prospective study of 987 medical and surgical patients in Monash Medical Center, Clarke and colleagues found diagnostic concordance of depression by referring doctor compared to a consultant psychiatrist was at $74 \%$ [43] with a false-positive rate of $41 \%$ and a false-negative rate of $15 \%$. This finding was replicated in several other studies [44-48]. Judd et al. found slightly better concordance of depression diagnosis in HIV patients (79 \%) with false-positive rate of $20 \%$ and falsenegative rate of $23 \%$. Dilts et al. found low accuracy only in depression diagnosis but not cognitive impairment or substance use disorder. This difference may be due to hospital doctors finding difficulty in identifying clinical depression in physically unwell patients [44]. Canuto and colleagues suggest concordance in diagnosis of clinical depression between psychiatrist and other doctors increases with severity of depression and younger age [49]. Depression is, however not the only mental illness poorly recognised by hospital doctors. Drug and alcohol issues were also frequently missed by hospital doctors [50], although anxiety and psychotic disorders were found to have the lowest diagnostic concordance in a 5 year study [51].

There are differences in estimates of mental illness prevalence among hospital doctors of different specialties. Mezey and Kellet's survey revealed that surgeons and gynaecologists were less likely to refer than their medical physician counterparts [33]. This was supported by reviews of referrals by surgical, obstetric and gynaecological doctors in several studies [52, 53]. Collating findings of Cohen-Cole and Friedman's study with Mezey and Kellet's, lower referral rates from surgeons, obstetricians and gynaecologists may be a result of poorer recognition of psychiatric issues. This view was supported by a study by Balestrieri et al. in medical and surgical inpatients in 2002 [54].

One may argue that lower referral rates from nonphysician doctors may be linked to patients being treated adequately, without the need for referral. This was not found to be the case by Fauman in his survey of 11 hospital doctors. Findings suggested a significantly larger proportion of physicians willing to treat psychiatric disorders than their surgical or obstetricgynaecological peers [55].

The difference in referral rates between specialties could also be accounted for by differences in expectations. In a 
questionnaire to 77 hospital doctors, De-Nour found that physicians tend to expect liaison service where psychiatrists participate actively in case conferences and routine management of patients [56]. This was in contrast to surgeons who expect a consultation service, where a psychiatrist advises on psychiatric management and diagnosis.

While the focus had been on presence of mental illness in patients, when assessment of competency was involved, many factors could increase referrals. Jourdan and Glickman found that over $25 \%$ of patients referred to their CLP service were for assessment of competency [57]. This same group of patients had no mental illness and three quarters of them were found to be competent. Jourdan and Glickman explained that the fear and anxiety of doctors about medico-legal consequences, and poor understanding of management when patients refuse treatment were possible reasons for increased referrals.

\section{Patient factors}

The presence of a psychiatric history increases the likelihood of referral. Fenichel and Murphy examined the decision-making process around making a psychiatric referral in the emergency department [58]. It was found that non-psychiatric staff often based their decision of referral on past psychiatry history if the patient presents with mild to moderate symptoms. In a study by Pritchard in 1972, patients with a psychiatric history are three times more likely to be referred for psychiatric consultation. However, Pritchard suggested that if the patient had previous contact with the psychiatric team in the same hospital, they might not be referred to CLP [37]. This was supported by lowered referral rates for patients with previous psychiatric contact in same hospital but did not reach statistical significance (Table 3).

Referral is more likely to happen if the patient is of younger age. Marcus and team looked at data from 327

Table 3 Patient factors possibly influencing referrals to CLP

\begin{tabular}{ll}
\hline Patient factors & \\
\hline Increase CLP referral & 1. Past psychiatric history [58] \\
& $\begin{array}{l}\text { 2. Young age [37, 59, 60] } \\
\text { 3. Urban setting [59] }\end{array}$ \\
4. Functional psychosis [37] \\
Decrease CLP referral & $\begin{array}{l}\text { 1. Organic psychosis [37] } \\
\text { 2. Previous psychiatric contact at same } \\
\text { Unclear influence }\end{array}$ \\
& $\begin{array}{l}\text { 1. Personality disorder (earlier referral) [62] } \\
\text { 2. Depression (delayed referral) [62] }\end{array}$ \\
& 3. Race and socio-economic status [63, 64] \\
& 4. Stigma [65]
\end{tabular}

American hospitals and found that age was inversely correlated with psychiatric referral rates [59]. Other studies have supported the inverse correlation of age to referrals [37, 60, 61]. The same study from Marcus et al. did not find gender of patients to be useful as predictors to psychiatric referrals [59]. However, patients in urban settings were more likely to be referred. This was attributed to a significantly higher psychiatrist-to-population ratio in urban regions [59].

The psychiatric diagnosis of the patient may predict likelihood of CLP referral. Patients with functional psychotic diagnoses (including schizophrenia and psychotic depression) were more likely to be referred to CLP [37]. Patients with psychosis from organic causes (such as dementia and delirium) were less likely to be referred [37]. In a prospective study of 712 referrals over a five-year period examining timing of referrals, presence of personality disorder was found to predict earlier referral. This was in contrast to presence of depression where a delayed referral was more likely [62]. Although timing of the referral does not inform us of whether a referral has been made, one may expect previous poor recognition of depression from a non-psychiatrist as discussed earlier to have delayed and prevented referrals.

Patient's race and their socio-economic status may influence psychiatric referrals. In a 1982 review of CLP referrals in a major teaching hospital, Craig found that white patients were more likely to be referred than non-white patients when an active liaison service was present [63]. However, once referred, services rendered to all patients by CLP were of no difference. Low referral rates exist similarly across all races if an active liaison service was not present. Craig suggested that this association may be as a result of higher emotional distress in lower socioeconomic groups, which was unfortunately associated with non-white patients presenting to this teaching hospital. Collins and colleagues looked at referral patterns among different ethnic-cultural groups in San Diego Medical Center [64]. They found lower referral rates for Hispanics compared to other groups (Anglos, Blacks and Asians). Different ethnic groups were also more likely to be referred for different conditions. For example, requests for evaluation of depression and suicides were higher in Hispanics, and much reduced in Blacks. The authors were not able to draw conclusions from these results and suggested more research into cultural factors that may influence manifestations of poor mental health and CLP referrals.

The perceived stigma by hospital doctors identified by Mezey and Kellet may not be present from the patient's perspective. Klein and team interviewed 48 medical 
inpatients and found that $81 \%$ were either moderately to very agreeable to having a psychiatric consultation [65].

\section{Discussion}

This review is the first to closely examine the possible factors reported in the literature that could influence CLP inpatient referrals. These studies were from diverse health care systems in different areas of the world. Of the thirty-three articles that stated their country of origin, thirteen of the studies originate from the US, six were from UK, five were from Europe other than UK (Germany, Ireland, Italy and Switzerland), four were from Australia and five were from Asia (Japan, Iran, Israel, South Korea, and Taiwan). There is a lack of research in this area from South America and Africa, which may reflect the lack of prioritisation for CLP services or research in these continents.

It is difficult to comment on hospital factors that might influence the generalisability of this review. However, factors such as hospital type (e.g., tertiary referral, specialist, regional); service population or catchment area; and level of non-CLP staff training may affect the application of these findings in various settings. While some studies in this review did describe inclusion of non-tertiary/tertiary, regional, private or geriatric hospitals, others were not clear in their description. We would expect CLP service utilisation by hospital doctors to be different depending on their service population and location. Therefore, the review reflected a global perspective of the literature available and may not apply to individual health systems.

Despite a review of the past fifty years, only thirtyfive studies were included. This may reflect lack of research into direct factors influencing CLP referrals. Lack of rigorous research into this topic could also explain the paucity of research included in this review. For example, a significant number of studies reported cross-sectional referral patterns of their respective CLP hospital service. These studies provided no new perspective and did not offer explanations for referral barriers.

Most of the articles found in this review were of low methodological quality, mainly comprising of surveys or retrospective chart reviews. The mix of studies included sixteen retrospective chart reviews, eight surveys, seven prospective studies, two reports of subjective experiences, one epidemiological study, and one meta-analysis. Only seven of the articles were published in the last ten years, suggesting the lack of recent research. Most of the surveys looking at the referrers' perspectives were published from 1970s to 1980s. This could reflect the early struggle of CLP to improve engagement with other medical specialties. Modern CLP services may not require direct patient referrals from hospital settings. The availability of outpatient CLP services may lower inpatient referral rates but increase overall number of CLP referrals.

Studies using surveys did not explain how individual items on the surveys were formulated. It was possible that survey items may reflect potential confirmation and selection bias from study authors. Validation data was rarely presented, so there may also be validity issues; where survey responses did not accurately reflect the perspectives of hospital doctors. No qualitative study has yet been performed to investigate the viewpoints of referrers and users of CLP services. This may represent an important knowledge gap for future research.

It is acknowledged that the literature search was performed by only the first author and selection bias in identification of articles is possible. However, the purpose of the review was to understand any factors published in the literature that could influence CLP referrals. Selection of articles was based on stated criteria but erred on the side of being over-inclusive. Missing articles, if any, were more likely due to human error.

The challenge for increasing psychiatric referrals may be quite similar in the primary care setting. Several inpatient barriers to psychiatric referral echoed barriers found in primary care, such as availability of psychiatrist [66], time pressure [66], poor communication with psychiatrist $[67,68]$ and poor recognition of mental illness by primary care physicians $[69,70]$. There may be considerable opportunity for future research that would be applicable to both inpatient CLP and primary care settings.

Comparing referral rates to prevalence of mental illness among hospital inpatients, it is clear that most inpatients with psychiatric comorbidities do not get referred by their treating team. The systemic factors found in the review suggested that quality of engagement is likely to influence referral rates [30-35]. Quality of engagement may involve a more active and communicative CLP service whose presence is clearly felt by the referrers. It may also involve building good working relationship with the referring team. If referrers feel that CLP consultation could bring benefits, they are more likely to continue referring. Many CLP services recognise this and use referrer satisfaction as an outcome measure for performance [71].

Quality of engagement may improve through means other than CLP service delivery. For example, research collaboration, outpatient CLP work and collaborative/ integrated care with CLP are some methods to 
improve engagement with other specialties [72, 73]. There were no studies investigating the direct influence of these methods on inpatient CLP referrals rates. This is understandable given the complexity of confounders in hospital systems, complicating any potential research into the area.

Placement of mental health nurses in a liaison role may be beneficial. Allied health professionals such as social workers and nurses may spend more time with patients. There is some evidence that with training and adequate staffing, nurses may improve on detection of mental illness [74]. Liaison work using CLP allied health professionals may pick up referrals missed by hospital doctors. Future research could investigate the impact of CLP allied health professionals on referral rates.

While a lack of hospital protocols or policies to guide CLP referrals may contribute to poor referral rates, systemic strategies that seek to increase referrals may bring unintended consequences. Introduction of any strategies should be considered with care. For example, mandatory CLP referrals for inpatients with psychiatric comorbidities, could strain poorly resourced CLP teams. This may lead to poor rapport with referrers and decrease quality of engagement. This strategy would also depend heavily on the referrer's ability to recognise mental illness, which had been shown to be lacking [33, 42-51, 54].

In terms of referrer factors, the review showed an at-risk group of hospital doctors who were less likely to refer their patients. These doctors include those of surgery and obstetrics-gynaecology subspecialties. Young, pre-specialist certified doctors were also less likely to make CLP referral. Considerations could be made to increase education, collaboration and communication to these at-risk doctor groups to increase CLP referrals.

Hospital doctor's ability to recognise and diagnose psychiatric conditions affects referral rate. In support of this, an exploratory study by Shortell and Daniels looked at internists in private practice and their psychiatric referrals [75]. They found that internists who were qualified specialist, older and had more years in practice are more likely to refer their patients. Higher referral rates may also come from experienced doctors who were more apt at recognising mental illness.

In contrast, younger doctors who were not yet qualified specialist and had spent less time in practice may be referring fewer patients $[33,75]$. A positive association may exist between self-perceived abilities to manage psychiatric issues and low referral rates. It was uncertain if young doctors' self-perceived ability to manage psychiatric conditions were reflective of their true capabilities. Further studies could shed light on this issue.

Stigma and patient preference were often raised as referral barriers by hospital doctors. As illustrated by Klein's study on medical inpatients, patients often do not hold the same view as their doctors [65]. It would be important for the education of hospital doctors, so that referrals were not obstructed by their own perception of mental illness stigma.

Younger patients with functional psychosis were more likely to be referred. This implied that other patient groups such as geriatric population or patients with delirium or dementia may be neglected. Although there is an increasing demand for CLP services by the geriatric population in recent years [76, 77], these patients are at risk of missing on psychiatric care.

Two studies have investigated the impact of race and ethnicity on CLP referrals. While statistically significant differences were found, these studies were of an epidemiological nature that could only suggest an association rather than direct causality. Socioeconomic status may be confounding the results and authors of these two studies were careful not to draw early conclusions. The impact of racial profiling by hospital doctors may be important for CLP services. Patients, regardless of their ethnicity or socio-economic status, should not be disadvantaged and be denied mental health care while hospitalised. Education of hospital doctors could correct this issue.

The review highlighted several patient groups that may be at risk. Collaborative screening of these vulnerable inpatient groups may be beneficial in providing fair mental health care.

\section{Conclusion}

CLP presents an opportunity to improve health outcomes for inpatients and reduce burden on the health care system, but data shows that this service is currently underutilised. Understanding the potential barriers to CLP referral is an important first step in improving referral rates. Although there is research in this area, it is of limited quality. There is no qualitative research from referrers' perspective, though such research may improve understanding of barriers to CLP referrals in the future. Education could be provided to at-risk hospital doctors to better recognise mental illness in their patients. Collaborative screening of vulnerable groups could prevent inpatients from missing out on psychiatric care. CLP clinicians should use the knowledge gained from this review to encourage quality engagement with referrers. 


\section{Appendix}

Table 4 Summary of articles included, details of the included articles including country, participants, study design and findings

\begin{tabular}{|c|c|c|c|c|}
\hline $\begin{array}{l}\text { Author/s, Date } \\
\text { (In order of } \\
\text { appearance) }\end{array}$ & Country, Setting & $\begin{array}{l}\text { Participants } \\
\text { (type and number) }\end{array}$ & Study design & Findings \\
\hline $\begin{array}{l}\text { Brown \& Cooper } \\
1987[30]\end{array}$ & UK, general hospital & 1,140 inpatient referrals & $\begin{array}{l}\text { Retrospective review of } \\
\text { referrals in 1973, 1976, } 1979\end{array}$ & $\begin{array}{l}\text { Dedicated CLP service increases } \\
\text { referrals. }\end{array}$ \\
\hline $\begin{array}{l}\text { McCartney et al. } \\
1989[31]\end{array}$ & $\begin{array}{l}\text { US, university } \\
\text { hospital }\end{array}$ & $\begin{array}{l}11,713 \text { gynaecologic oncology } \\
\text { and other cancer patients }\end{array}$ & $\begin{array}{l}\text { Retrospective review of } \\
\text { referrals, before and after } \\
\text { introduction of gynaecologic } \\
\text { oncology liaison program }\end{array}$ & $\begin{array}{l}\text { Introduction of CLP program increases } \\
\text { referrals }\end{array}$ \\
\hline $\begin{array}{l}\text { Thompson et al. } \\
1990 \text { [32] }\end{array}$ & US, Colorado & $\begin{array}{l}200 \text { non-psychiatrist doctors } \\
\text { (35\% response rate) }\end{array}$ & 16 item survey & $\begin{array}{l}\text { Most common reasons for not } \\
\text { referring: Other mental health } \\
\text { practitioners do just as well, lack of } \\
\text { communication by psychiatrist, stigma, } \\
\text { accessibility }\end{array}$ \\
\hline $\begin{array}{l}\text { Mezey \& Kellett } \\
1971 \text { [33] }\end{array}$ & UK, London & $\begin{array}{l}106 \text { consultants from } 6 \\
\text { hospitals ( } 83 \% \text { response rate) }\end{array}$ & 10 item survey & $\begin{array}{l}\text { Most common reasons for not } \\
\text { referring: Patient's preference, stigma, } \\
\text { accessibility, poor rapport with } \\
\text { psychiatrist. Surgery, Obstetrics and } \\
\text { Gynaecology subspecialty associated } \\
\text { with less referrals }\end{array}$ \\
\hline $\begin{array}{l}\text { Diefenbacher } \\
2001[35]\end{array}$ & $\begin{array}{l}\text { Germany, Berlin, } \\
\text { Rudolf Virchow } \\
\text { Hospital }\end{array}$ & 208 inpatient referrals & $\begin{array}{l}\text { Observational study of referral } \\
\text { patterns over } 1 \text { year following } \\
\text { introduction of CLP }\end{array}$ & $\begin{array}{l}\text { Increase in referrals from medical and } \\
\text { surgical wards. Decrease in urgent } \\
\text { referrals, suggesting increased } \\
\text { tolerance towards psychiatric } \\
\text { conditions. }\end{array}$ \\
\hline $\begin{array}{l}\text { Camus et al. } \\
2003 \text { [34] }\end{array}$ & $\begin{array}{l}\text { Switzerland, } \\
\text { university hospital }\end{array}$ & 176 medical inpatients & $\begin{array}{l}\text { Prospective cohort study on } \\
\text { collaborative CLP screening }\end{array}$ & Referral rates increase from 4 to $32 \%$. \\
\hline $\begin{array}{l}\text { Jo et al. } \\
2011[36]\end{array}$ & $\begin{array}{l}\text { Korea, Seoul tertiary } \\
\text { general hospitals }\end{array}$ & $\begin{array}{l}310 \text { patients with suicide } \\
\text { attempts }\end{array}$ & Questionnaire on patients & $\begin{array}{l}\text { No significant difference in referral rate } \\
\text { between history of suicide attempts } \\
\text { and non-suicide attempters. }\end{array}$ \\
\hline $\begin{array}{l}\text { Pritchard } \\
1972[37]\end{array}$ & $\begin{array}{l}\text { UK, London general } \\
\text { hospital }\end{array}$ & 252 patients & $\begin{array}{l}\text { Retrospective chart review of } \\
\text { patients with psychiatric } \\
\text { diagnosis }\end{array}$ & $\begin{array}{l}\text { Patients with suicidal attempts have } \\
\text { highest referral rates. Young age, } \\
\text { functional psychosis associated with } \\
\text { increased referral. Organic psychosis } \\
\text { and previous psychiatric contact } \\
\text { associated with decreased referral. }\end{array}$ \\
\hline $\begin{array}{l}\text { Caplan et al. } \\
2008[38]\end{array}$ & US & N/A & Opinion piece & $\begin{array}{l}\text { Work pressure suggested with } \\
\text { increased CLP referrals }\end{array}$ \\
\hline
\end{tabular}

$\begin{array}{llll}\text { Wood \& Bisson } & \begin{array}{l}\text { UK, maxillofacial } \\ \text { surgery unit }\end{array} & \begin{array}{l}58 \text { patients with cancers of } \\ \text { head and neck }\end{array} & \begin{array}{l}\text { Subjective reporting of } \\ \text { experience with mental health } \\ \text { nurse liaison }\end{array}\end{array}$

Cohen-Cole et al. US, North Carolina 1982 [40] Memorial Hospital

407 hospital doctors (34\%

\section{$2011[52$}

Taiwan, general hospital

Ni Mhaolain et at. 2008 [53]

Ireland, genera hospital

Balestrieri et al. 2002 [54]
Italy, general hospital 1039 general inpatients response rate)

111 obstetric and gynaecologic patients

96 surgical patients

37 item questionnaire

Retrospective chart review

Prospective evaluation of anxiety and depression in surgical patients

Cross sectional investigation of prevalence of depression among hospital patients
Increased referrals suggested with use of mental health nurse liaison.

Physicians in internal medicine and family medicine tend to recognise patients with more psychological issues.

Most hospital doctors are comfortable with managing psychiatric illness.

Low referral rates from obstetric and gynaecologic department.

High prevalence of depression and anxiety in surgical patients.

Identification of depression by hospital doctors in one third of all cases. 
Table 4 Summary of articles included, details of the included articles including country, participants, study design and findings (Continued)

\begin{tabular}{lll}
\hline Fauman 1983 & US, private urban & $\begin{array}{l}265 \text { hospital doctors (41.9\% } \\
\text { hospital }\end{array}$ \\
[55] & response rate)
\end{tabular}

Hamdieh et al. 2015 [41]

Iran, Tehran, general hospital

300 non-psychiatric doctors

\begin{tabular}{|c|c|c|}
\hline $\begin{array}{l}\text { Jourdan \& } \\
\text { Glickman } \\
1991 \text { [57] }\end{array}$ & US, general hospital & 380 psychiatric referrals \\
\hline $\begin{array}{l}\text { Cepoiu et al. } \\
2008[42]\end{array}$ & $\mathrm{N} / \mathrm{A}$ & $\begin{array}{l}36 \text { articles (comprising of } \\
50935 \text { inpatients) }\end{array}$ \\
\hline $\begin{array}{l}\text { Clarke et al. } \\
1995 \text { [43] }\end{array}$ & $\begin{array}{l}\text { Australia, Melbourne, } \\
\text { Monash Medical } \\
\text { Centre }\end{array}$ & $\begin{array}{l}987 \text { medical and surgical } \\
\text { patients }\end{array}$ \\
\hline
\end{tabular}

Dilts et al.

UK, York Hospital

2003 [44]

Judd et al.

1997 [45]

Ryan et al.

1995 [46]

Yamada et al.

2012 [47]

Boland et al.

1996 [48]

Canuto et al.

2015 [49]

Smith et al.

1995 [50]

Su et al.

2011 [51]

De-Nour

1979 [56]

Fenichel \&

Murphy

1985 [58]
Japan, Tokyo 172 geriatric inpatients

Metropolitan Geriatric

Hospital

US, teaching hospital

4396 inpatients referred for consultations

Switzerland University hospital of Geneva

Australia, Melbourne, 2347 inpatient referrals Monash Medical

Centre

Taiwan, region

general hospital

Israel

77 hospital doctors

12095 patients presenting to

US, Hospital of the

University of

Pennsylviania

emergency

department (64.3\% response rate)

8 item questionnaire

Retrospective chart review

346 medical inpatient consultations

392 HIV/AIDS patients referred for CLP

50 geriatric inpatients

Prospective cohort study examining agreement

between psychiatrist and

geriatricians on depression and dementia

Prospective diagnostic review of CLP consultations

Retrospective chart review

Prospective cohort study

Retrospective chart review

Retrospective chart review

Survey

Retrospective chart review
Internists are more willing to refer

suicidal attempts than surgeons. Internists are more willing to ask for consultations than surgeons for all other mental health conditions.

Hospital doctors were more comfortable requesting for psychiatric consultations than managing psychiatric conditions themselves.

High referral rates for determination of competency. Fear of medico-legal consequences and referrer's anxiety suggested as reasons for referral rates.

Sensitivity was found to be $36.4 \%$ and specificity was $83.7 \%$

Diagnostic concordance of depression $74 \%, 41 \%$ false positive rate and $15 \%$ false negative rate.

Initial diagnosis of cognitive disorders and substance use disorder is likely to be correct. Initial diagnosis of depression is wrong in half the cases.

Diagnostic concordance of depression was $79 \%, 20 \%$ false positive rate and $23 \%$ false negative rate

Some evidence suggesting lower recognition of depression by geriatricians

Almost half of patients with depression diagnosed by referrers were found to be delirium.

$40 \%$ of patients initially identified by referrer to be depressed were found not to be depressed by psychiatry consultants

$40 \%$ of patients initially referred for depression were diagnosed with depression by CLP.

$56 \%$ of patients suspected by psychiatrist for substance use disorder were missed by referrers.

Only $41.5 \%$ of initial physician's impression matches with psychiatrist's final impression

Surgeons prefer consultation service, Physicians prefer liaison service.

Patient with psychiatric history were associated with psychiatric referral 
Table 4 Summary of articles included, details of the included articles including country, participants, study design and findings (Continued)

\begin{tabular}{|c|c|c|c|c|}
\hline $\begin{array}{l}\text { Marcus et al. } \\
1987 \text { [59] }\end{array}$ & $\begin{array}{l}\text { US, } 327 \text { general } \\
\text { hospitals }\end{array}$ & $\begin{array}{l}37221 \text { patients with diabetes, } \\
19484 \text { patients with hip } \\
\text { fractures, } 25116 \text { patients with } \\
\text { COPD, } 11770 \text { patients with } \\
\text { CABG }\end{array}$ & Retrospective chart review & $\begin{array}{l}\text { Age negatively correlated to psychiatric } \\
\text { consultation. Patients in urban settings } \\
\text { are more likely to receive psychiatric } \\
\text { consultation }\end{array}$ \\
\hline $\begin{array}{l}\text { Popkin et al. } \\
1984 \text { [60] }\end{array}$ & US & 111 geriatric inpatients & Retrospective chart review & $\begin{array}{l}\text { Compared to younger population, } \\
\text { geriatric population was less often } \\
\text { referred }\end{array}$ \\
\hline $\begin{array}{l}\text { Handrinos et al. } \\
1998 \text { [62] }\end{array}$ & $\begin{array}{l}\text { Australia, Dandenong } \\
\text { hospital }\end{array}$ & 712 inpatient referrals & Retrospective chart review & $\begin{array}{l}\text { Personality disorder predicts earlier } \\
\text { referral. Depression predicts delayed } \\
\text { referral. }\end{array}$ \\
\hline $\begin{array}{l}\text { Craig } 1982 \\
\text { [63] }\end{array}$ & $\begin{array}{l}\text { US, university } \\
\text { hospital (not named) }\end{array}$ & 362 inpatient referrals & Retrospective chart review & $\begin{array}{l}\text { White patients are more likely to be } \\
\text { referred. Once referred, there is no } \\
\text { difference in care to white or non- } \\
\text { white population. }\end{array}$ \\
\hline $\begin{array}{l}\text { Collins et al. } \\
1992[64]\end{array}$ & $\begin{array}{l}\text { US, San Diego } \\
\text { Medical Centre }\end{array}$ & $\begin{array}{l}476 \text { patients receiving } \\
\text { psychiatric consultations } \\
\text { compared with } 14620 \text { without } \\
\text { psychiatric consultations }\end{array}$ & Retrospective chart review & Low referral rate for Hispanic patients. \\
\hline $\begin{array}{l}\text { Klein et al. } \\
1996 \text { [65] }\end{array}$ & $\begin{array}{l}\text { US, Montefiore } \\
\text { Medical Centre }\end{array}$ & 48 inpatients & Survey & $\begin{array}{l}81 \% \text { agreeable to psychiatric consultation } \\
\text { if their primary care doctor felt it was } \\
\text { indicted }\end{array}$ \\
\hline
\end{tabular}

\section{Abbreviation \\ CLP: Consultation-Liaison Psychiatry}

\section{Acknowledgements}

Not applicable.

\section{Funding}

James Cook University and Townsville Hospital Health Service provided support in kind for the time and resources required for the review.

\section{Availability of data and materials}

All data generated or analysed during this study are included in this published article and its Appendix

\section{Authors' contributions}

KYC gathered and thematically analysed the studies included in this review. RE was a significant contributor in writing the manuscript. SL co-analysed the studies and contributed to the writing of the manuscript. All authors read and approved the final manuscript.

\section{Consent for publication}

Not applicable.

\section{Ethics approval and consent to participate}

Not applicable.

Received: 22 July 2016 Accepted: 28 October 2016

Published online: 09 November 2016

\section{References}

1. Australian Institute of Health and Welfare. Comorbidity of mental disorders and physical conditions 2007. Cat. no. PHE 155. Canberra: Australian Institute of Health and Welfare; 2012. http://www.aihw.gov.au/publicationdetail/?id=10737421146.

2. Silverstone PH. Prevalence of psychiatric disorders in medical inpatients. J Nerv Ment Dis. 1996;184(1):43-51.

3. Arolt $V$, Driessen M, Dilling $H$. The Lübeck general hospital study. I: Prevalence of psychiatric disorders in medical and surgical inpatients. Int J Psychiatry Clin Pract. 1997;1(3):207-16.

4. Martucci M, Balestrieri M, Bisoffi G, Bonizzato P, Covre MG, Cunico L, De Francesco M, Marinoni MG, Mosciaro C, Piccinelli M, et al. Evaluating psychiatric morbidity in a general hospital: a two-phase epidemiological survey. Psychol Med. 1999;29(4):823-32

5. Hansen MS, Fink P, Frydenberg M, Oxhøj M-L, Søndergaard L, Munk Jørgensen P. Mental disorders among internal medical inpatients: prevalence, detection, and treatment status. J Psychosom Res. 2001;50(4):199-204

6. Schulberg HC, McClelland M, Burns BJ. Depression and physical illness: the prevalence, causation, and diagnosis of comorbidity. Clin Psychol Rev. 1987; 7(2):145-67.

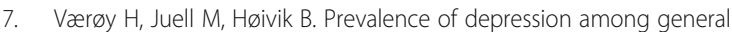
hospital surgical inpatients. Nord J Psychiatry. 2003;57(1):13-6.

8. Rentsch D, Dumont P, Borgacci S, Carballeira Y, deTonnac N, Archinard M, Andreoli A. Prevalence and treatment of depression in a hospital department of internal medicine. Gen Hosp Psychiatry. 2007;29(1):25-31.

9. Moayedoddin B, Rubovszky G, Mammana L, Jeannot E, Sartori M, Garin N, Andreoli A, Canuto A, Perrier A. Prevalence and clinical characteristics of the DSM IV major depression among general internal medicine patients. Eur J Intern Med. 2013;24(8):763-6.

10. Fava GA, Pilowsky I, Pierfederici A, Bernardi M, Pathak D. Depression and illness behavior in a general hospital: a prevalence study. Psychother Psychosom. 1982;38(1):141-53.

11. Levenson JL, Hamer RM, Rossiter LF. Relation of psychopathology in general medical inpatients to use and cost of services. Am J Psychiatry. 1990; 147(11):1498-503.

12. Saravay SM, Steinberg MD, Weinschel B, Pollack S, Alovis N. Psychological comorbidity and length of stay in the general hospital. Am J Psychiatry. 1991:148(3):324-9.

13. Fulop G, Strain JJ, Fahs MC, Schmeidler J, Snyder S. A prospective study of the impact of psychiatric comorbidity on length of hospital stays of elderly medical-surgical inpatients. Psychosomatics. 1998;39(3):273-80.

14. Furlanetto LM, Da Silva RV, Bueno JR. The impact of psychiatric comorbidity on length of stay of medical inpatients. Gen Hosp Psychiatry. 2003;25(1):14-9.

15. Koopmans GT, Donker MCH, Rutten FHH. Length of hospital stay and health services use of medical inpatients with comorbid noncognitive mental disorders: a review of the literature. Gen Hosp Psychiatry. 2005;27(1):44-56.

16. Lipowski ZJ. Consultation-liaison psychiatry in general hospital. Compr Psychiatry. 1971;12(5):461-5.

17. Lipowski ZJ. Consultation-liaison psychiatry: an overview. Am J Psychiatry. 1974;131(6):623-30.

18. Lipowski ZJ Current trends in consultation-liaison psychiatry. Can J Psychiatry. 1983;28(5):329-38. 
19. Bower P, Sibbald B. Do consultation-liaison services change the behavior of primary care providers? A review. Gen Hosp Psychiatry. 2000;22(2):84-96.

20. Levitan SJ, Kornfeld DS. Clinical and cost benefits of liaison psychiatry. Am J Psychiatry. 1981;138(6):790-3.

21. Desan PH, Zimbrean PC, Weinstein AJ, Bozzo JE, Sledge WH. Proactive psychiatric consultation services reduce length of stay for admissions to an inpatient medical team. Psychosomatics. 2011;52(6):513-20.

22. Cassem NH, Hackett TP. Psychiatric consultation in a coronary care unit. Ann Intern Med. 1971;75(1):9-14.

23. Gala C, Rigatelli M, De Bertolini C, Rupolo G, Gabrielli F, Grassi L. A multicenter investigation of consultation-liaison psychiatry in Italy. Italian CL Group. Gen Hosp Psychiatry. 1999;21 (4):310-7.

24. Huyse FJ, Herzog T, Lobo A, Malt UF, Opmeer BC, Stein B, de Jonge P, van Dijck R, Creed F, Crespo MD, et al. Consultation-Liaison psychiatric service delivery: results from a European study. Gen Hosp Psychiatry. 2001;23(3):124-32.

25. Rothenhausler HB, Ehrentraut S, Kapfhammer HP. Changes in patterns of psychiatric referral in a German general hospital: results of a comparison of two 1-year surveys 8 years apart. Gen Hosp Psychiatry. 2001;23(4):205-14.

26. Dhossche DM, Lorant Z. Psychiatric consultations in a southern university hospital. South Med J. 2002:95(4):446-9.

27. Diefenbacher A, Strain JJ. Consultation-liaison psychiatry: stability and change over a 10-year-period. Gen Hosp Psychiatry. 2002;24(4):249-56,

28. Bourgeois JA, Wegelin JA, Servis ME, Hales RE. Psychiatric diagnoses of 901 inpatients seen by consultation-liaison psychiatrists at an academic medical center in a managed care environment. Psychosomatics. 2005;46(1):47-57.

29. Hales RE, Polly $\mathrm{S}$, Bridenbaugh $H$, Orman D. Psychiatric consultations in a military general hospital. A report on 1065 cases. Gen Hosp Psychiatry. 1986; 8(3):173-82.

30. Brown A, Cooper AF. The impact of a liaison psychiatry service on patterns of referral in a general hospital. Br J Psychiatry. 1987;150:83-7.

31. McCartney CF, Cahill P, Larson DB, Lyons JS, Wada CY, Pincus HA. Effect of a psychiatric liaison program on consultation rates and on detection of minor psychiatric disorders in cancer patients. Am J Psychiatry. 1989;146(7):898-901.

32. Thompson TL, Wise TN, Kelley AB, Mann LS. Improving psychiatric consultation to nonpsychiatrist physicians. Psychosomatics. 1990;31(1):80-4.

33. Mezey AG, Kellett JM. Reasons against referral to the psychiatrist. Postgrad Med J. 1971:47(548):315-9.

34. Camus V, Viret C, Porchet A, Ricciardi P, Bouzourene K, Burnand B. Effect of changing referral mode to C-L Psychiatry for noncognitively impaired medical inpatients with emotional disorders. J Psychosom Res. 2003;54(6):579-85.

35. Diefenbacher A. Implementation of a psychiatric consultation service: a single-site observational study over a 1-year-period. Psychosomatics. 2001; 42(5):404-10.

36. Jo SJ, Lee MS, Yim HW, Kim HJ, Lee K, Chung HS, Cho J, Choi SP, Seo YM. Factors associated with referral to mental health services among suicide attempters visiting emergency centers of general hospitals in Korea: does history of suicide attempts predict referral? Gen Hosp Psychiatry. 2011;33(3):294-9.

37. Pritchard M. Who sees a psychiatrist? A study of factors related to psychiatric referral in the general hospital. Postgrad Med J. 1972:48(565):645-52.

38. Caplan JP, Querques J, Freudenreich O, Kontos N. Work-hour regulation: collateral damage to consultation psychiatry. Am J Psychiatry. 2008;165(7): 915. author reply 916.

39. Wood S, Bisson Jl. Experience of incorporating a mental health service into patient care after operations for cancers of the head and neck. Br J Oral Maxillofac Surg. 2004;42(2):149-54.

40. Cohen-Cole SA, Friedman CP. Attitudes of nonpsychiatric physicians toward psychiatric consultation. Hosp Community Psychiatry. 1982;33(12):1002-5.

41. Hamdieh M, Banihashem S, Beyraghi N, Abbasinejad M, Hagh-Ranjbar F. Physicians' attitudes toward integrating consultation-liaison psychiatric services in four major general hospitals in Tehran. Gen Hosp Psychiatry. 2015;37(5):456-8.

42. Cepoiu M, McCusker J, Cole MG, Sewitch M, Belzile E, Ciampi A. Recognition of depression by non-psychiatric physicians - a systematic literature review and meta-analysis. J Gen Intern Med. 2008:23(1):25-36.

43. Clarke DM, McKenzie DP, Smith GC. The recognition of depression in patients referred to a consultation-liaison service. J Psychosom Res. 1995; 39(3):327-34.
44. Dilts Jr SL, Mann N, Dilts JG. Accuracy of referring psychiatric diagnosis on a consultation-liaison service. Psychosomatics. 2003:44(5):407-11.

45. Judd FK, Cockram A, Mijch A, McKenzie D. Liaison psychiatry in an HIV/AIDS unit. Aust N Z J Psychiatry. 1997;31(3):391-7.

46. Ryan DH, Blackburn P, Lawley D, Ellis A, Musil J, Kendrick DC. Depression and dementia in geriatric inpatients: diagnostic comparisons between psychiatrists, geriatricians and test scores. Int I Geriatr Psychiatry. 1995;10(6):447-56.

47. Yamada K, Hosoda M, Nakashima S, Furuta K, Awata S. Psychiatric diagnosis in the elderly referred to a consultation-liaison psychiatry service in a general geriatric hospital in Japan. Geriatr Gerontol Int. 2012;12(2):304-9.

48. Boland RJ, Diaz S, Lamdan RM, Ramchandani D, McCartney JR. Overdiagnosis of depression in the general hospital. Gen Hosp Psychiatry. 1996;18(1):28-35.

49. Canuto A, Gkinis G, DiGiorgio S, Arpone F, Herrmann FR, Weber K Agreement between physicians and liaison psychiatrists on depression in old age patients of a general hospital: influence of symptom severity, age and personality. Aging \& Mental Health. 2016;20(10):1092-8.

50. Smith GC, Clarke DM, Handrinos D. Recognising drug and alcohol problems in patients referred to consultation-liaison psychiatry. Med J Aust. 1995; 163(6):307, 310-2.

51. Su JA, Tsai CS, Hung TH, Chou SY. Change in accuracy of recognizing psychiatric disorders by non-psychiatric physicians: five-year data from a psychiatric consultation-liaison service. Psychiatry Clin Neurosci. 2011; 65(7):618-23.

52. Lin HL, Chou HH, Liu CY, Hsu SC, Hsiao MC, Juang YY. The role of consulting psychiatrists for obstetric and gynecologic inpatients. Chang Gung Med J. 2011;34(1):57-64

53. Ni Mhaolain AM, Butler JS, Magill PF, Wood AE, Sheehan J. The increased need for liaison psychiatry in surgical patients due to the high prevalence of undiagnosed anxiety and depression. Ir J Med Sci. 2008;177(3):211-5.

54. Balestrieri M, Bisoffi G, Tansella M, Martucci M, Goldberg DP. Identification of depression by medical and surgical general hospital physicians. Gen Hosp Psychiatry. 2002;24(1):4-11.

55. Fauman MA. Psychiatric components of medical and surgical practice, II: Referral and treatment of psychiatric disorders. Am J Psychiatry. 1983;140(6):760-3.

56. De-Nour AK. Attitudes of physicians in a general hospital towards psychiatric consultation service. Ment Health Soc. 1979;5(3-4):215-23.

57. Jourdan JB, Glickman L. Reasons for requests for evaluation of competency in a municipal general hospital. Psychosomatics. 1991;32(4):413-6.

58. Fenichel GS, Murphy JG. Factors that predict psychiatric consultation in the emergency department. Med Care. 1985;23(3):258-65.

59. Marcus SE, Pincus HA, Goldman HH, Wallen J. Factors associated with the use of psychiatric consultations in short-term general hospitals. Psychosom Med. 1987;49(5):508-22.

60. Popkin MK, Mackenzie TB, Callies AL. Psychiatric consultation to geriatric medically ill inpatients in a university hospital. Arch Gen Psychiatry. 1984; 41(7):703-7.

61. Citero Vde A, Nogueira-Martins LA, Lourenco MT, Andreoli SB. Clinical and demographic profile of cancer patients in a consultation-liaison psychiatric service. Sao Paulo Med J. 2003;121(3):111-6.

62. Handrinos D, McKenzie D, Smith GC. Timing of referral to a consultationliaison psychiatry unit. Psychosomatics. 1998;39(4):311-7.

63. Craig TJ. Racial patterns in liaison psychiatry. J Natl Med Assoc. 1982;74(12): $1211-5$.

64. Collins D, Dimsdale JE, Wilkins D. Consultation/liaison psychiatry utilization patterns in different cultural groups. Psychosom Med. 1992;54(2):240-5.

65. Klein DA, Saravay SM, Pollack S. The attitudes of medical inpatients toward psychiatric consultation: a re-examination. Int J Psychiatry Med. 1996;26(3): 287-93.

66. Trude S, Stoddard JJ. Referral gridlock: primary care physicians and mental health services. J Gen Intern Med. 2003;18(6):442-9.

67. Tanielian TL, Pincus HA, Dietrich AJ, Williams Jr JW, Oxman TE, Nutting P, Marcus SC. Referrals to psychiatrists. Assessing the communication interface between psychiatry and primary care. Psychosomatics. 2000;41(3):245-52.

68. Avant RF. Psychiatric consultation and referral. Med Clin North Am. 1988; 72(4):929-35.

69. Ormel J, Koeter MJ, van den Brink W, van de Willige G. Recognition, management, and course of anxiety and depression in general practice. Arch Gen Psychiatry. 1991;48(8):700-6. 
70. Kirmayer $L$, Robbins $J M$, Dworkind $M$, Yaffe MJ. Somatization and the recognition of depression and anxiety in primary care. Am J Psychiatry. 1993;150(5):734-41.

71. Lavakumar M, Gastelum ED, Hussain F, Levenson J, Wharton RN, Muskin PR, Shapiro PA. How do you know your consult service is doing a good job? Generating performance measures for $\mathrm{C}-\mathrm{L}$ service effectiveness. [Erratum appears in Psychosomatics. 2014 Jan-Feb;55(1):108 Note: Gastelum, Emily J [corrected to Gastelum, Emily D]]. Psychosomatics. 2013;54(6):567-74.

72. Ogawa A, Nouno J, Shirai Y, Shibayama O, Kondo K, Yokoo M, Takei H, Koga H, Fujisawa D, Shimizu K, et al. Availability of psychiatric consultation-liaison services as an integral component of palliative care programs at Japanese cancer hospitals. Jpn J Clin Oncol. 2012;42(1):42-52.

73. Smith GC. From consultation-liaison psychiatry to integrated care for multiple and complex needs. Aust N Z J Psychiatry. 2009;43(1):1-12.

74. Kutney-Lee A, Aiken LH. Effect of nurse staffing and education on the outcomes of surgical patients with comorbid serious mental illness. Psychiatr Serv. 2008:59(12):1466-9. doi:10.1176/ps.2008.59.12.1466.

75. Shortell SM, Daniels RS. Referral relationships between internists and psychiatrists in fee-for-service practice: an empirical examination. Med Care. 1974;12(3):229-40

76. Anderson D, Nortcliffe M, Dechenne S, Wilson K. The rising demand for consultation-liaison psychiatry for older people: comparisons within Liverpool and the literature across time. Int J Geriatr Psychiatry. 2011;26(12):1231-5.

77. Brown EL, Raue PJ, Nassisi P, Bruce ML. Increasing recognition and referral of the depressed elderly. Home Healthc Nurse. 2001;19(9):558-64.

\section{Submit your next manuscript to BioMed Central and we will help you at every step:}

- We accept pre-submission inquiries

- Our selector tool helps you to find the most relevant journal

- We provide round the clock customer support

- Convenient online submission

- Thorough peer review

- Inclusion in PubMed and all major indexing services

- Maximum visibility for your research

Submit your manuscript at www.biomedcentral.com/submit

) Biomed Central 